\title{
RaceRunning training improves stamina and promotes skeletal muscle hypertrophy in young individuals with cerebral palsy
}

Emma Hjalmarsson ${ }^{1,2}$, Rodrigo Fernandez-Gonzalo ${ }^{3}$, Cecilia Lidbeck ${ }^{1,4}$, Alexandra Palmcrantz ${ }^{2}$, Angel Jia ${ }^{1}$, Ola Kvist ${ }^{5,6}$, Eva Pontén ${ }^{1,4}$ and Ferdinand von Walden ${ }^{1 *}$

\begin{abstract}
Background: Individuals with cerebral palsy (CP) are less physically active, spend more time sedentary and have lower cardiorespiratory endurance as compared to typically developed individuals. RaceRunning enables highintensity exercise in individuals with CP with limited or no walking ability, using a three-wheeled running bike with a saddle and a chest plate for support, but no pedals. Training adaptations using this type of exercise are unknown.

Methods: Fifteen adolescents/young adults (mean age 16, range 9-29, 7 females/8 males) with CP completed 12 weeks, two sessions/week, of RaceRunning training. Measurements of cardiorespiratory endurance (6-min RaceRunning test (6-MRT), average and maximum heart rate, rate of perceived exertion using the Borg scale (BorgRPE)), skeletal muscle thickness (ultrasound) of the thigh (vastus lateralis and intermedius muscles) and lower leg (medial gastrocnemius muscle) and passive range of motion (pROM) of hip, knee and ankle were collected before and after the training period.
\end{abstract}

Results: Cardiorespiratory endurance increased on average 34\% (6-MRT distance; pre $576 \pm 320 \mathrm{~m}$ vs. post $723 \pm$ $368 \mathrm{~m}, p<0.001$ ). Average and maximum heart rate and Borg-RPE during the 6-MRT did not differ pre vs. post training. Thickness of the medial gastrocnemius muscle increased $9 \%$ in response to training $(p<0.05)$ on the more-affected side. Passive hip flexion increased $(p<0.05)$ on the less-affected side and ankle dorsiflexion decreased $(p<0.05)$ on the more affected side after 12 weeks of RaceRunning training.

Conclusions: These results support the efficacy of RaceRunning as a powerful and effective training modality in individuals with $\mathrm{CP}$, promoting both cardiorespiratory and peripheral adaptations.

Keywords: Aerobic exercise, Cardiorespiratory endurance, Cerebral palsy, Skeletal muscle, Skeletal muscle hypertrophy

\section{Background}

Cerebral palsy $(\mathrm{CP})$ is the most common childhood motor disability, with a prevalence of around $2.0-2.5$ per 1000 live births [1]. The damage to the brain is permanent and non-progressive, but the severity and nature of the clinical

\footnotetext{
* Correspondence: Ferdinand.von.walden@ki.se

'Neuropediatrics Unit, Department of Women's and Children's Health, Karolinska Institutet, Tomtebodavägen 18a, 17177 Stockholm, Sweden Full list of author information is available at the end of the article
}

manifestations often change over time [2]. With the Gross Motor Function Classification System (GMFCS) children and youth with CP can be classified on a 5-level scale based on their self-initiated movement with particular emphasis on sitting, walking, and wheeled mobility [3, 4]. While individuals functioning at GMFCS level I participate in a great variety of activities, children with more severe motor function difficulties (GMFCS IV-V) have restricted options for physical activity participation

(c) The Author(s). 2020 Open Access This article is licensed under a Creative Commons Attribution 4.0 International License, which permits use, sharing, adaptation, distribution and reproduction in any medium or format, as long as you give appropriate credit to the original author(s) and the source, provide a link to the Creative Commons licence, and indicate if changes were made. The images or other third party material in this article are included in the article's Creative Commons. licence, unless indicated otherwise in a credit line to the material. If material is not included in the article's Creative Commons licence and your intended use is not permitted by statutory regulation or exceeds the permitted use, you will need to obtain permission directly from the copyright holder. To view a copy of this licence, visit http://creativecommons.org/licenses/by/4.0/. The Creative Commons Public Domain Dedication waiver (http://creativecommons.org/publicdomain/zero/1.0/) applies to the data made available in this article, unless otherwise stated in a credit line to the data. 
including hydrotherapy, horseback riding and boccia, all examples of activities with low cardiorespiratory demands. Individuals with $\mathrm{CP}$ are known to be less physically active and spend more time sedentary as compared to typically developing (TD) individuals [5]. The level of physical activity negatively correlates to motor function as classified according to the GMFCS classification system, both in terms of physical education participation at school and regular physical activity during leisure time [6].

Muscle mass is significantly lower in children with $\mathrm{CP}$ as compared to TD children, including muscles in the lower limbs [7, 8]. Moreover, individuals with CP typically have lower cardiorespiratory endurance as compared to TD individuals [9]. It is well known that aerobic capacity increases with endurance training in TD individuals and positively influences quality of life and overall health status [10]. CP is associated with an increased risk of multiple disorders linked to premature aging and inactivity such as coronary artery disease and type 2 diabetes [11, 12]. Stimulating individuals with CP to regularly participate in moderate to high-intensity activities would likely increase physical fitness and thereby reduce the risk of disease, especially since it has been shown that physical activity in adults with CP is related to their physical activity as adolescents [13]. Secondary musculoskeletal problems including decreased range of motion are common in children with CP $[14,15]$. Reduced knee and hip joint extension are known to influence function and are associated with gait inefficiency in adolescents with CP [16]. Moreover, in a study by van der Linden and colleagues reduced pROM in knee extention and skeletal muscle spasticity were found to be negatively associated with RaceRunning performance in CP [17].

The RaceRunner is a three-wheeled running bike with a saddle and a chest plate for support but no pedals [17-19] and can be used by individuals in GMFCS level I-V (see supplementary figure 1). It enables highintensity exercise for individuals with $\mathrm{CP}$ who (may) have limited or no walking ability [18]. However, training adaptations using this type of exercise are unknown.

Therefore, we performed a 12-week RaceRunning training study to address the following research questions: 1) Does cardiorespiratory endurance increase with training in individuals with CP? 2) Does skeletal muscle thickness increase with RaceRunning training? 3) Is the passive range of motion of the hip, knee and ankle affected by RaceRunning training?

\section{Methods}

\section{Study design}

This intervention study aims to evaluate the effects of RaceRunning training twice per week for 12 weeks in children, adolescents and young adults with CP. The tests and evaluations took place during two weeks before and two weeks after the training period. In addition, 6min RaceRunning test (6-MRT) [18] was performed at week four and eight (Fig. 1).

\section{Participants and recruitment}

Fifteen $(n=15)$ children/adolescents/young adults (mean age 16, range 9-29, 7 females/8 males) with CP completed 12 weeks, two sessions per week, of RaceRunning

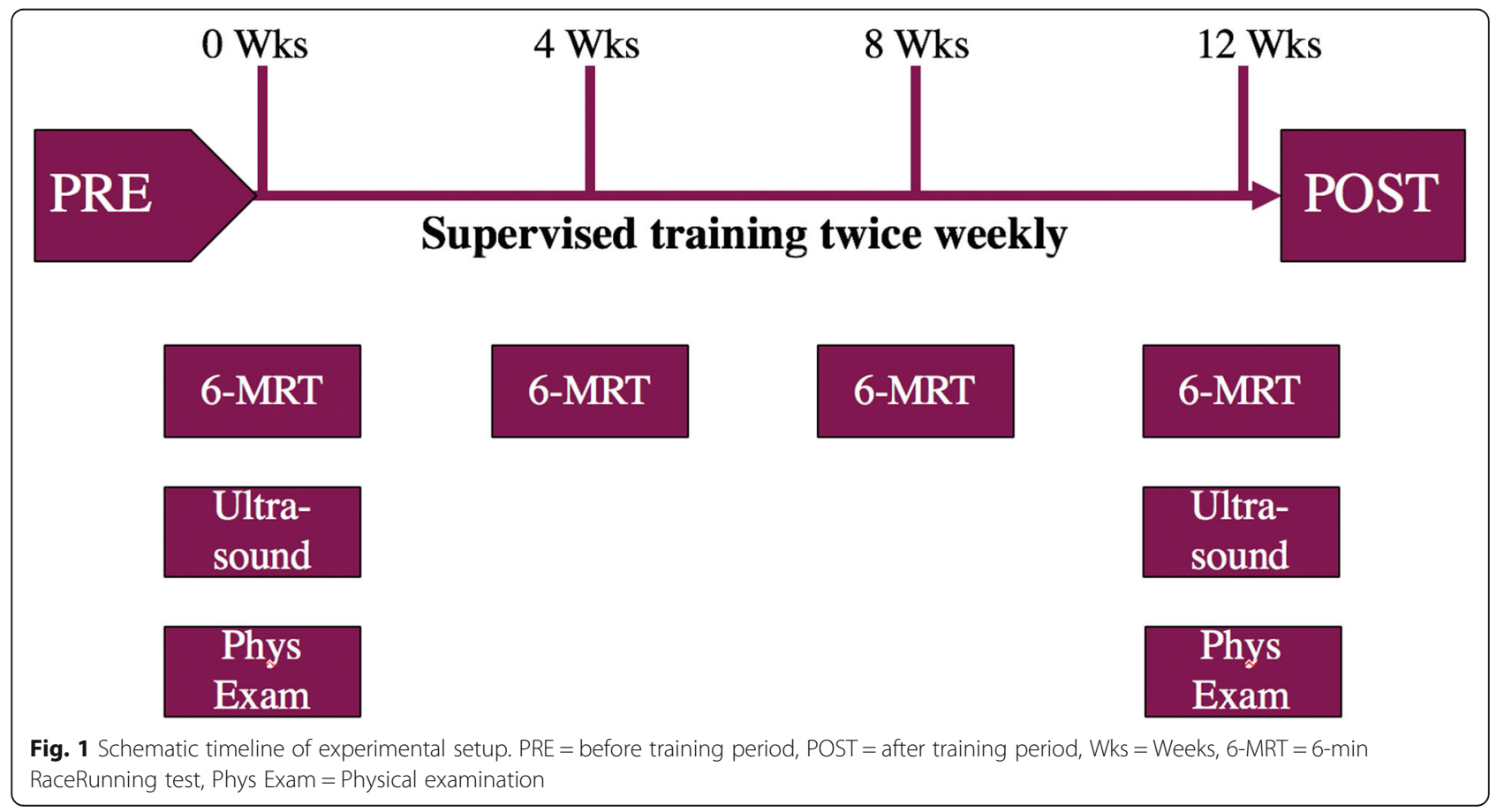


training (subject characteristics in Table 1). Recruitment of participants took place via RaceRunning sport associations in three cities in Sweden; Uppsala, Stockholm and Västerås, and were based on interest and inclusion/exclusion criteria. Inclusion criteria were children and young adults with CP, GMFCS I-IV within the age span 7-35 years. In order to avoid initial learning effects, and/ or effects of adjusting the RaceRunner to the individual, all participants were accustomed to the sport for at least three months before the intervention. The amount of previous practice varied between participants (three months to > three years), but none had followed any structured, supervised training program before the commencement of the study. Exclusion criteria were orthopedic surgery or injections of botulinum toxin during or three months prior to the study. In addition, interventions aiming at reducing skeletal muscle spasticity such as history of selective dorsal rhizotomy or intrathecal baclofen were also seen as exclusion criteria. Eighteen participants were enrolled to participate in the study, but three participants were excluded due to additional diagnoses or incomplete training and/or evaluations.

\section{Intervention}

The training period consisted of supervised RaceRunning exercise twice per week for 12 weeks, one h per session, together with the local club at an indoor track and field facility. Participants were instructed to follow a specific training program during each session. The program consisted of five blocks: warm-up (light jog), short distance intervals (sprints of 40-100 m), long distance intervals (continuous running for three to ten min at medium to high speed), technique exercises (60 m slalom course with eight to ten markers or $60 \mathrm{~m}$ run alternating using only the right/left leg), and wind-down (light jog). Participants trained in groups consisting of 5-15 individuals. Participants were encouraged to work at an intensity that made them sweat and out of breath, but no specific

Table 1 Subject characteristics

\begin{tabular}{ll}
\hline Variable & $\begin{array}{l}\text { Description of participants }(n= \\
15)\end{array}$ \\
\hline Age & 16 [9-29] \\
Gender (female / male) & $7 / 8$ \\
BMI & $18,6[13,5-22,6]$ \\
Type of CP; Spastic / Dyskinetic / & $9 / 5 / 1$ \\
Ataxia & $1 / 3 / 4 / 7$ \\
GMFCS-level; / / / III / IV & $8 / 0 / 2 / 0 / 4 / 1$ \\
FMS 5 m 1 / 2/3/4/5/6 & $8 / 4 / 0 / 0 / 3 / 0$ \\
FMS 50 m 1 / 2/3/4/5/6 & $12 / 1 / 0 / 0 / 2 / 0$ \\
FMS 500 m 1 / 2/3/4/5/6
\end{tabular}

Subject characteristics, mean [range]. BMI Body Mass Index, GMFCS Gross Motor Function Classification System, FMS Functional Mobility Scale, with number of participants in each category target heart rate or target level of perceived exertion (Borg-RPE) was set during the training sessions. Depending on the training site (Stockholm, Uppsala or Västerås) the coach was either a physiotherapist or bachelor/master degree in sports science. One training session per week was recorded using a trip computer with speed sensor (Garmin Edge 25, Garmin, United States) and a chest strap (Garmin) enabling data collection of distance travelled (meters), time spent in motion with the RaceRunner (minutes) during each session, speed (meters/second), and average and maximum heart rate during the training session (beats/minute) $[20,21]$.

\section{6-min RaceRunning test for cardiorespiratory endurance}

To assess gains in cardiorespiratory endurance the 6min RaceRunning test (6-MRT) was used [18]. This test measures the total distance covered with the RaceRunner during six min. The participants were allowed to warm up for five min on the RaceRunner prior to the test and were then instructed to run as far as possible during six min. Participants performed the 6-MRT a total of four times; 1 ) before the training period, 2) at week four, 3) week eight and 4) after the training period. Distance, and average and maximal heart rate were measured at all time points. Data were collected as described above using the trip computer (Garmin Edge 25) and the distance was verified using a measuring wheel. Level of perceived exertion (Borg-RPE) was rated using the 620 Borg scale [22]. Two participants did not perform the 12w 6-MRT. Data from the eight week 6-MRT were used for pre vs post training evaluation for these participants.

\section{Ultrasound examination for skeletal muscle thickness}

Muscle thickness was assessed in the calf (medial gastrocnemius muscle) and thigh (vastus lateralis and intermedius muscles of the quadriceps) in both legs using ultrasound (Siemens acuson s2000, Siemens, Erlangen, Germany) with a built-in function for measurements of skeletal muscle. Several images (5-8) were taken of each muscle, to ensure consistency of measured values. The ultrasound measurements were performed before and after 12 weeks of RaceRunning training by the same radiologist. The leg with the thinnest medial gastrocnemius muscle was denoted as the more affected leg [23].

\section{Physical examination}

Participants underwent a physical examination of the lower limbs by the same physiotherapist before and after the training period. At the first examination, data collection included classification of motor function using the GMFCS [4]. Passive range of motion (pROM) was measured in the hip, knee and ankle with a goniometer in standardized positions [24]. In addition, muscle 
spasticity was assessed according to the Modified Ashworth scale [25] with the grading $0,1,+1,2,3$ or 4 . After 12 weeks of RaceRunning training, the physical examination was performed in 14 participants. One participant did not come to the post physical examination and was therefore excluded from the pROM analysis.

\section{Statistics}

Data corresponding to 6-MRT, heart rate (average and maximum) and distance covered were analyzed using a general linear model with repeated measures, with time (pre, 4-wk, 8-wk, 12-wk) as within-subject factor. Potential differences between pre- and post-training in muscle thickness were assessed employing paired t-tests. Top speed was analyzed with a general linear model with repeated measures, with time (pre, 12-wk) as within-subject factor. Normal distribution of data was verified using the Shapiro-Wilk test. A Wilcoxon signed Rank test was used to compare pROM and a Fischer's exact test was used to compare spasticity in the lower limbs before and after the training period. Data were analyzed using SPSS v.25 (Chicago, Illinois) and are presented as mean \pm SD unless stated otherwise. Statistical significance was set at $p<0.05$.

\section{Results}

\section{Cardiorespiratory endurance (or RaceRunning capacity)}

Participants were on average in motion 25 min (range 4-42 min) during the training sessions. The cardiorespiratory training intensity averaged 136 heart beats per minute (bpm) (range 112-166 bpm), i.e. 69\% (range 58-82\%) of estimated maximum heart rate (208$0.7 x a g e ;$ Table 2). Average maximum heart rate during the training sessions was $168 \mathrm{bpm}$ (range 139-197 bpm) or $82 \%$ (range $74-98 \%$ ) of estimated maximum heart rate.

Following 12-weeks of RaceRunning training, all participants had increased their running distance by on average 34\% (6-min RaceRunning test distance; pre $576 \pm 320 \mathrm{~m}$ vs. post $723 \pm 368 \mathrm{~m}, p<0.001$, Fig. 2a). Mean top speed also increased pre vs. post 12-weeks of RaceRunning training $(3.3 \pm 1.5 \mathrm{~m} / \mathrm{s}$ vs. $3.7 \pm 1.2 \mathrm{~m} / \mathrm{s}, p<$ 0.05 , Fig. 2b) corresponding to an average $21 \%$ (range 6 to $+85 \%)$. Average ( $149 \pm 35$ vs. $156 \pm 27, p=0.667)$ and maximum $(171 \pm 27$ vs. $177 \pm 19, p=0.840)$ heart rate during the 6-MRT did not differ pre vs. post training. Similarly, the level of perceived exertion during the 6-MRT, as rated using the Borg scale, did not change (pre-6MRT-score $8.2 \pm 3.1$ and $8.1 \pm 3.5, p=0.491$ and after-6MRT-score $14.7 \pm 3.8$ and $15.1 \pm 3.7, p=0.947$ ).

\section{Skeletal muscle thickness}

Thickness of the medial gastrocnemius muscle in the more affected leg increased significantly after 12 weeks of RaceRunning training $(11.6 \pm 2.7 \mathrm{~mm}$ vs. $12.4 \pm 2.6$ $\mathrm{mm}, p=0.005$, Fig. $3 \mathrm{~b}$ ), but no significant change was found in the same muscle of the less affected leg (12.5 \pm

Table 2 Training intensity

\begin{tabular}{|c|c|c|c|c|c|c|c|}
\hline Subject & Age & $\begin{array}{l}\text { Type of } \\
\text { CP }\end{array}$ & GMFCS & $\begin{array}{l}\text { Average time in motion } \\
\text { per training hour (minutes) }\end{array}$ & $\begin{array}{l}\text { Average HR (bpm) (\% of } \\
\text { age corrected HRmax) }\end{array}$ & $\begin{array}{l}\text { Average of HRmax (bpm) (\% } \\
\text { of age corrected HRmax) }\end{array}$ & $\begin{array}{l}\text { Top measured HR (bpm) (\% } \\
\text { of age corrected HRmax) }\end{array}$ \\
\hline 1 & $10-14$ & Dyskinetic & 4 & 23 & $136(69 \%)$ & $169(85 \%)$ & 208 (105\%) \\
\hline 2 & $10-14$ & Dyskinetic & 4 & 29 & 123 (61\%) & 164 (82\%) & 183 (91\%) \\
\hline 3 & $15-19$ & Dyskinetic & 4 & 22 & 127 (65\%) & 158 (81\%) & 189 (97\%) \\
\hline 4 & $15-19$ & Dyskinetic & 4 & 34 & 135 (69\%) & 170 (87\%) & 213 (109\%) \\
\hline 5 & $20-24$ & Dyskinetic & 3 & 42 & 149 (77\%) & 175 (90\%) & 189 (97\%) \\
\hline 6 & $25-29$ & Spastic bi & 2 & 24 & 154 (81\%) & 176 (93\%) & 185 (97\%) \\
\hline 7 & $25-29$ & Spastic bi & 4 & 4 & 115 (61\%) & $139(74 \%)$ & 163 (87\%) \\
\hline 8 & $20-24$ & Spastic bi & 3 & 29 & 112 (58\%) & 156 (81\%) & 198 (103\%) \\
\hline 9 & $5-9$ & $\begin{array}{l}\text { Spastic } \\
\text { uni }\end{array}$ & 1 & 21 & 166 (82\%) & 186 (92\%) & 204 (101\%) \\
\hline 10 & $10-14$ & Spastic bi & 3 & 24 & 140 (70\%) & 166 (83\%) & 184 (92\%) \\
\hline 11 & $10-14$ & Spastic bi & 2 & 31 & 158 (79\%) & 197 (98\%) & 208 (104\%) \\
\hline 12 & $10-14$ & Spastic bi & 3 & 28 & $148(74 \%)$ & 176 (88\%) & 196 (99\%) \\
\hline 13 & $10-14$ & Spastic bi & 4 & 17 & 132 (66\%) & 170 (85\%) & 196 (98\%) \\
\hline 14 & $10-14$ & Spastic bi & 4 & 24 & 122 (61\%) & $152(76 \%)$ & 188 (94\%) \\
\hline 15 & $5-9$ & Ataxic & 2 & 18 & 126 (62\%) & 161 (80\%) & 196 (97\%) \\
\hline \multicolumn{3}{|c|}{ Mean value } & & 25 & 136 (69\%) & 168 (85\%) & 193 (98\%) \\
\hline \multicolumn{3}{|c|}{ Range: $\min$ - max } & & $4-42$ & $112-166(58-82 \%)$ & 139-197 (74-98\%) & 163-213 (87-109\%) \\
\hline
\end{tabular}




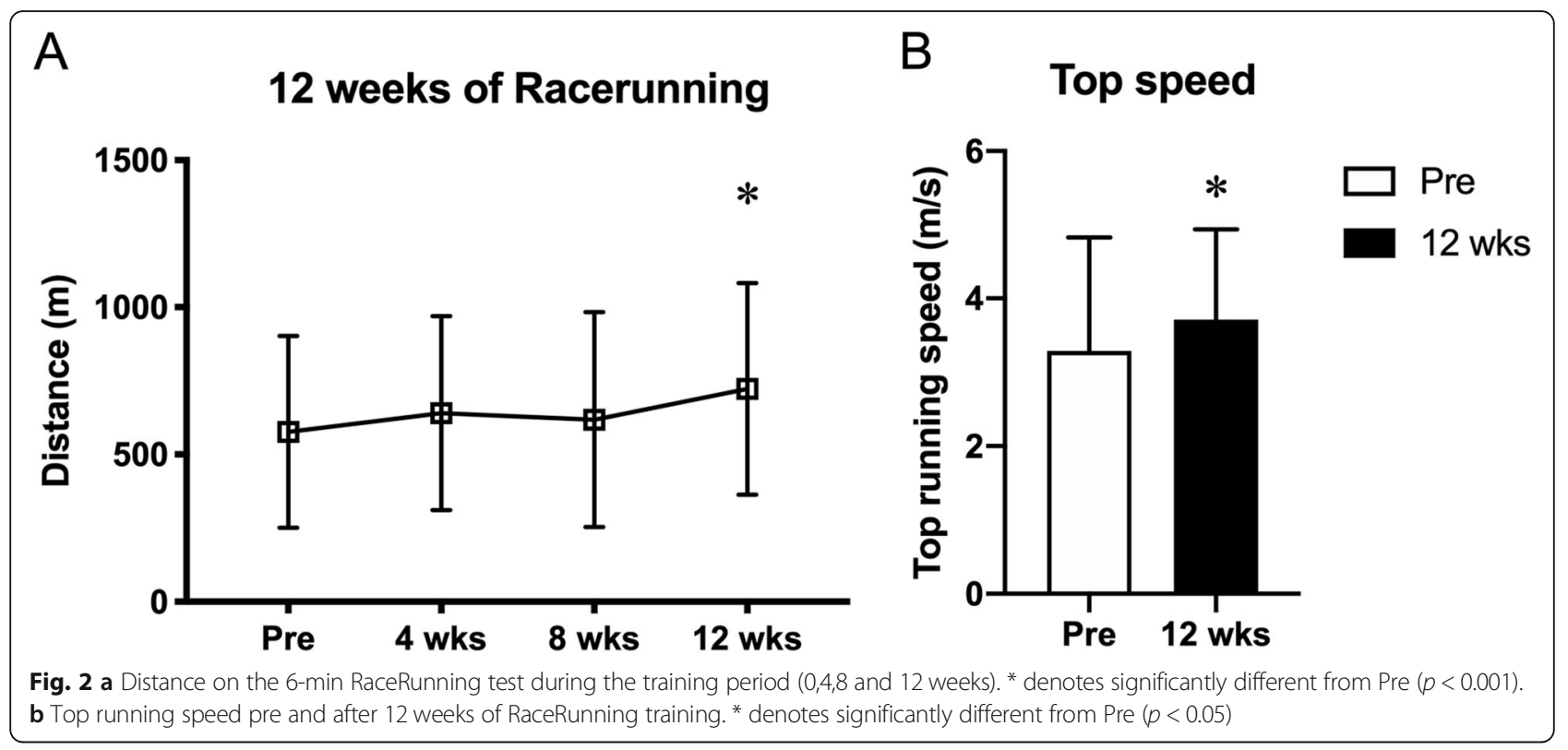

$2.7 \mathrm{~mm}$ vs. $12.6 \pm 2.6 \mathrm{~mm}, p=0.251$, Fig. 3a). No significant change was found in thickness of the vastus lateralis and intermedius muscles in any leg (more-affected $23.6 \pm 6.1 \mathrm{~mm}$ vs. $23.6 \pm 7.0 \mathrm{~mm}, p=0.389$; less affected $26.6 \pm 6.5 \mathrm{~mm}$ vs. $26.0 \pm 7.0 \mathrm{~mm}, p=0.269)$.

\section{Physical examination: passive range of motion and spasticity}

After the training period, passive hip flexion in the lessaffected leg increased as compared to pre-training measurements (median $[\min , \max ] 125^{\circ}\left[70^{\circ}, 150^{\circ}\right]$ vs. $130^{\circ}$ $\left.\left[100^{\circ}, 150^{\circ}\right], p=0.015\right)$, but no significant difference was found in the more-affected hip $\left(128^{\circ}\left[80^{\circ}, 150^{\circ}\right]\right.$ vs. $125^{\circ}$ $\left.\left[110^{\circ}, 150^{\circ}\right], p=0.080\right)$. Passive ankle dorsiflexion in the more-affected limb decreased pre vs. post training $\left(10^{\circ}\right.$ $\left[-15^{\circ}, 35^{\circ}\right]$ vs $\left.10^{\circ}\left[-20^{\circ}, 35^{\circ}\right], p=0.026\right)$. No significant difference was found in the less-affected ankle $\left(10^{\circ}\left[-5^{\circ}\right.\right.$, $\left.30^{\circ}\right]$ vs. $10^{\circ}\left[0^{\circ}, 35^{\circ}\right], p=0.218$, Table 3$)$. There was no significant difference in spasticity in the lower limbs before and after the training period (Supplementary table 1).

\section{Discussion}

Individuals with $\mathrm{CP}$ are known to be less physically active, spend more time sedentary and have lower cardiorespiratory endurance as compared to TD individuals. In order to counteract diseases associated with poor muscle health and a sedentary lifestyle, e.g. type- 2 diabetes and cardiovascular disease, physical activity modalities allowing for varying degrees of motor disability are warranted. There are currently not many physical exercise alternatives that promote cardiovascular adaptations for people with severe disabilities. RaceRunning enables highintensity exercise in individuals with $\mathrm{CP}$ with limited or no walking ability. Our data support the use of RaceRunning to increase cardiorespiratory fitness and promote skeletal muscle hypertrophy in affected limbs in individuals with $\mathrm{CP}$.

The main finding of the present study was that 12 weeks of RaceRunning training twice per week improves cardiorespiratory endurance on average $34 \%$ as compared to pre-training values. All participants included in the intervention improved their performance on the 6MRT, whereas average and maximal heart rate, as well as pre-post ratings on the Borg-RPE scale remained unchanged. We interpret this as evidence in favor of cardiorespiratory adaptation to exercise, as longer distance traveled during the 6-MRT at a fixed heart rate suggest either central adaptation (stroke volume) and/or peripheral adaptation (hemoglobin, myoglobin, mitochondrial content, muscle hypertrophy). Two studies investigating the results of aerobic training in children with $\mathrm{CP}$ have also reported that while oxygen consumption, $\mathrm{VO}_{2 \max }$, increased, the heart rate during the test situation remained the same [26, 27]. Our Borg-RPE data further support this view, as the Borg-RPE remained constant before and after the 12-week training period, whereas the performance on the 6-MRT improved. Our results are well in line with previous training studies investigating the effects of endurance exercise interventions in individuals with CP (GMFCS I-II). Training duration of six weeks to three months has been reported to result in improvements in peak oxygen consumption of $18-23 \%$ in adolescents with CP [27-29]. Longer periods of 


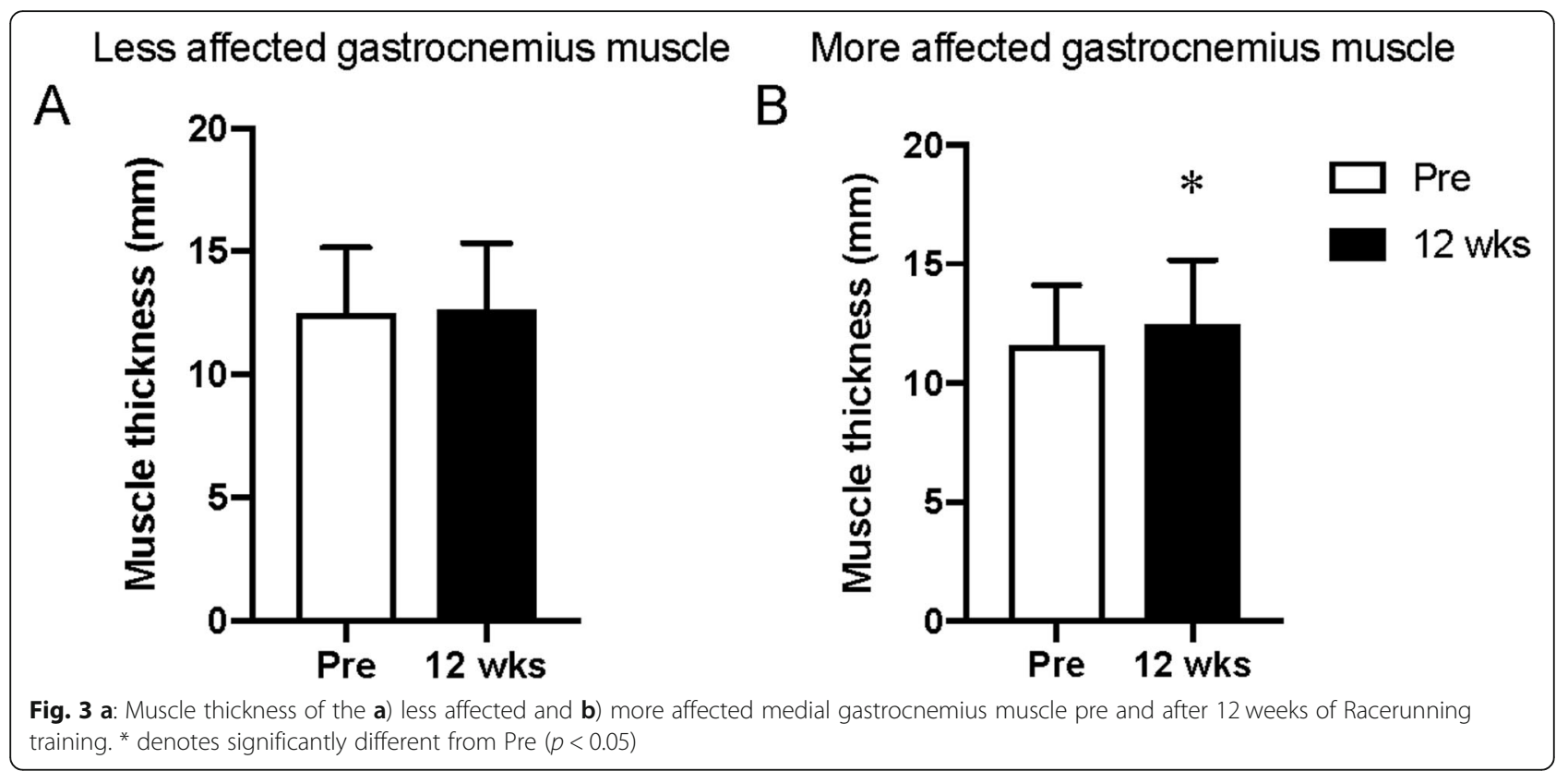

training (up to nine months) display $35-41 \%$ increments in aerobic performance [30, 31], suggesting a positive relationship between training duration and improvements in cardiorespiratory endurance. Berg performed one of the first longer training studies in school children with CP $(n=22)$, investigating the result of up to 16 months (range 1.5 months to 16 months) of aerobic training [32]. Twenty out of 22 participants increased their $\mathrm{VO}_{2 \max }$; 12 participants improved $>25 \%$ and the remaining eight participants by $10-15 \%$. A linear relationship between training duration and increase in $\mathrm{VO}_{2}$ max as a result of training (correlation coefficient 0.68) was observed in the study by Berg. With respect to recommendations by the American College of Sports Medicine (ACSM) regarding training frequency and duration [33], our study with a training intensity of $65 \%$ of age-corrected maximum heart rate, should have been performed three times per week rather than the actual two times per week. Training at this frequency is often hard for schoolchildren with $\mathrm{CP}$ who depend heavily on their families. However, as pointed out by Verschuren and colleagues, previous studies in which the actual training frequency did not meet the minimal recommendations for people with $\mathrm{CP}$, have nevertheless shown remarkable improvements in aerobic capacity [9]. This suggests that for sedentary and deconditioned individuals with $\mathrm{CP}$, an initial training dose of one to two times per week is likely sufficient, a frequency that can gradually be increased as adaptations occur. Our data supports this point of view and provide evidence that, given sufficient work

Table 3 passive range of motion pre vs post intervention

\begin{tabular}{|c|c|c|c|c|c|c|}
\hline & \multicolumn{3}{|c|}{ More-affected leg } & \multicolumn{3}{|c|}{ Less-affected leg } \\
\hline & $\begin{array}{l}\text { Before } \\
(n=14)\end{array}$ & $\begin{array}{l}\text { After } \\
(n=14)\end{array}$ & $p$-value & $\begin{array}{l}\text { Before } \\
(n=14)\end{array}$ & $\begin{array}{l}\text { After } \\
(n=14)\end{array}$ & $p$-value \\
\hline \multicolumn{7}{|c|}{ pROM, median [min, max] } \\
\hline Hip flexion & $128[80,150]$ & $125[110,150]$ & 0.080 & $125[70,150]$ & $130[100,150]$ & 0.015 \\
\hline Hip extension & $0[-30,15]$ & $2[-20,10]$ & 0.200 & $0[-30,20]$ & $0[-20,15]$ & 0.643 \\
\hline Hamstrings lenght & $125[100,145]$ & $122[100,150]$ & 0.560 & $125[105,160]$ & $125[110,160]$ & 0.660 \\
\hline Knee flexion & $155[60,155]$ & $155[85,155]$ & 0.414 & $155[80,155]$ & $155[75,155]$ & 0.655 \\
\hline Knee extension & $-15[-45,5]$ & $-18[-40,5]$ & 0.107 & $-10[-40,10]$ & $-15[-45,10]$ & 0.248 \\
\hline Ankle dorsiflexion & $10[-15,35]$ & $10[-20,35]$ & 0.026 & $10[-5,30]$ & $10[0,35]$ & 0.218 \\
\hline
\end{tabular}

Passive range of motion (pROM) in median [min, max] degrees, before and after a training period with RaceRunning ( $p$-level $<0.05$ indicated in bold). Negative values (-) indicate range of motion to less than neutral position of the joint 
intensity, a frequency of two times per week is effective in promoting cardiorespiratory endurance adaptations.

In addition to improving cardiorespiratory fitness, 12 weeks of RaceRunning training resulted in 9\% hypertrophy of the medial gastrocnemius muscle on the more affected side. This was an intriguing finding, as endurance exercise such as running is not traditionally seen as an activity promoting skeletal muscle growth. However, recent evidence suggests that low load exercise such as walking and biking can have anabolic properties in older, untrained individuals [34]. Harber and co-workers investigated the effect of a 12 week, twice per week, cycle ergometer training protocol at $60-80 \% \mathrm{VO}_{2}$-workload on skeletal muscle size on $>70$-year-old women [35]. Skeletal muscle fiber size increased on average $12 \%$ as a result of training in this cohort. Similarly, a study investigating the effects of six months of walking training on muscles in the lower limb reported increases in skeletal muscle thickness in sedentary to moderately active older adults [36]. On the contrary, active older men and women did not increase cross-sectional area (CSA) of the vastus lateralis muscle after ten weeks of walking training [37]. Collectively, these studies suggest that ambulatory activity with sufficient intensity $(>60 \%$ of the heart rate reserve) can result in increments of skeletal muscle size in older adults, but that the outcome is influenced by initial physical activity levels. It is well established that individuals with $\mathrm{CP}$ are known to be less physically active and spend more time sedentary as compared to typically developed individuals [5]. Moreover, skeletal muscle in CP was recently referred to as a model of premature aging in relation to sarcopenia and skeletal muscle dysfunction [38]. In this narrative review article, the authors highlighted evidence of poor muscle quality in individuals with $\mathrm{CP}$, e.g. increased intramuscular collagen content and inter- and intramuscular fat, and early atrophy predisposing for a sedentary life in adulthood. This is exemplified by that the vast majority (75\%) of ambulatory individuals with $\mathrm{CP}$ eventually stop walking by choice at adult age because of fatigue, inefficient ambulation and/or because using a wheelchair expanded their access to community activities [39]. Thus, we propose that a combination of a low level of every day activity and a low starting point with respect to skeletal muscle thickness might explain the hypertrophic response of the calf muscle on the more affected side following 12 weeks of RaceRunning training.

Van der linden and colleagues have reported that both reduced joint range of motion and increased muscle spasticity in the lower limb were negatively associated with speed [17]. In our study, we show that all participants, irrespectively of contractures and/or spasticity around the knee and/or ankle joint, where able to increase 6-MRT distance and top RaceRunning speed.
Passive hip flexion increased modestly after the training period. On the contrary, dorsiflexion of the ankle joint decreased after training, indicating that we cannot expect to slow down contracture formation simply by stimulating individuals with $\mathrm{CP}$ to participate in endurance sports. It should be noted that all changes in pROM pre vs. post training were small and that the clinical significance of these changes in degrees of movement, both positive and negative around the joint, can be questioned. Larger studies that monitor individuals over a longer period of time are needed to explore contracture formation and the effect of exercise induced skeletal muscle remodeling in cerebral palsy.

The current report should be viewed upon in the light of the following limitations. Our number of participants were small and heterogeneous with respect to RaceRunning experience and severity of the motor impairment. Therefore, future studies should aim at enrolling a larger number of individuals, with a more homogenous training background and include a control group. Likewise, as this was a real-world set study and not a hospital run intervention, all our participants were already accustomed to RaceRunning and participated based on interest and motivation which may have favorably affect our results.

\section{Conclusions}

A pre-post intervention study of 12 weeks of RaceRunning training improves cardiorespiratory endurance in individuals with CP. Moreover, RaceRunning stimulates skeletal muscle hypertrophy of the calf muscle. These results speak in favor of RaceRunning as a powerful and effective training modality in individuals with $\mathrm{CP}$ promoting both central and peripheral adaptations.

\section{Supplementary information}

Supplementary information accompanies this paper at https://doi.org/10. 1186/s12891-020-03202-8.

Additional file 1: Figure S1. Study participant running with the Racerunner. Photo used with permission.

Additional file 2: Table S1. Distribution of spasticity in the lower limb muscles assessed with the modified Ashworth scale and graded as 0, 1 , $+1,2,3$, or 4 , where 0 indicates no increase in muscle tone and 4 indicates marked increase in muscle tone, before and after a training period with RaceRunning ( $p$-level 0.05).

\section{Abbreviations}

6-MRT: 6-min RaceRunning test; ACSM: American College of Sports Medicine; Borg-RPE: Borg scale for rated perceived exertion; Bpm: Beats per minute; CP: Cerebral Palsy; CSA: Cross-sectional area; GMFCS: Gross Motor Function Classification System; pROM: Passive range of motion; TD: Typically developing; $\mathrm{VO}_{2 \text { max }}$ : Maximum oxygen uptake

\section{Acknowledgements}

The authors would like to extend their sincere gratitude to all participants and their families for taking part in the study. The assistance of Bachelor and Masters level students Olav Kvitastein, Liljar Már Kristjansson, Emma Grafford, 
Anna Jonsson Wastesson and Ulrika Kjellman is also greatly appreciated. The study was supported by grants from Stiftelsen Promobilia, Norrbacka-Eugenia Stiftelsen, RBUs forskningsstiftelse, Elsassfonden, Stiftelsen Samariten. Non of the listed funding bodies played any roles in the design of the study and collection, analysis, and interpretation of data and in writing the manuscript.

\section{Authors' contributions}

EH performed experiments, analyzed data, interpreted results, designed figures/tables, drafted manuscript, edited manuscript, approved final version of manuscript. RFG performed experiments, analyzed data, designed figures/ tables, edited manuscript, approved final version of manuscript. $\mathrm{CL}$ analyzed data, interpreted results, designed figures/tables, drafted manuscript, edited manuscript, approved final version of manuscript. AP performed experiments, edited manuscript, approved final version of manuscript. AJ performed experiments, analyzed data, interpreted results, approved final version of manuscript. OK performed experiments, analyzed data, interpreted results, edited manuscript, approved final version of manuscript. EP designed study, interpreted results, edited manuscript and approved final version of manuscript. FvW designed study, performed experiments, analyzed data, interpreted results, designed figures/tables, drafted manuscript, edited manuscript, approved final version of manuscript.

\section{Funding}

The study was supported by grants from Stiftelsen Promobilia (FvW), Norrbacka-Eugenia Stiftelsen (FvW), RBUs forskningsstiftelse (FvW), Elsassfonden (FvW), Stiftelsen Samariten (EH).

Open access funding provided by Karolinska Institute.

\section{Availability of data and materials}

The datasets generated and analyzed during the current study are not publicly available due risk of compromising individual privacy but are available from the corresponding author on reasonable request.

\section{Ethics approval and consent to participate}

The Regional Ethical Review Board in Stockholm, Sweden, approved the study. The study conformed to the standards set by the Declaration of Helsinki. Informed written consent was obtained from all participants and the parents of those younger than 18 years.

\section{Consent for publication}

Not applicable.

\section{Competing interests}

The authors declare that they have no competing interests.

\section{Author details}

${ }^{1}$ Neuropediatrics Unit, Department of Women's and Children's Health, Karolinska Institutet, Tomtebodavägen 18a, 17177 Stockholm, Sweden. ${ }^{2}$ Allied Health Professionals Function, Medical Unit Occupational Therapy and Physiotherapy, Karolinska University Hospital, Stockholm, Sweden. ${ }^{3}$ Department of Laboratory Medicine, Division of Clinical Physiology, Karolinska Institutet, and Unit of Clinical Physiology, Karolinska University Hospital, Stockholm, Sweden. ${ }^{4}$ Department of Pediatric Orthopaedic Surgery, Karolinska University Hospital, Stockholm, Sweden. ${ }^{5}$ Department of Pediatric Radiology, Karolinska University Hospital, Stockholm, Sweden. ${ }^{6}$ Clinical Pediatrics Unit, Department of Women's and Children's Health, Karolinska Institutet, Stockholm, Sweden.

\section{Received: 3 December 2019 Accepted: 11 March 2020}

Published online: 27 March 2020

\section{References}

1. Oskoui M, Coutinho F, Dykeman J, Jette N, Pringsheim T. An update on the prevalence of cerebral palsy: a systematic review and meta-analysis. Dev Med Child Neurol. 2013;55(6):509-19.

2. Rosenbaum P, Paneth $N$, Leviton $A$, et al. A report: the definition and classification of cerebral palsy April 2006. Dev Med Child Neurol Suppl. 2007;109:8-14

3. Palisano R, Rosenbaum P, Walter S, Russell D, Wood E, Galuppi B. Development and reliability of a system to classify gross motor function in children with cerebral palsy. Dev Med Child Neurol. 1997;39(4):214-23.
4. Palisano RJ, Rosenbaum P, Bartlett D, Livingston MH. Content validity of the expanded and revised gross motor function classification system. Dev Med Child Neurol. 2008;50(10):744-50.

5. Nooijen CF, Slaman J, Stam HJ, Roebroeck ME, Berg-Emons RJ, Learn2Move Research G. Inactive and sedentary lifestyles amongst ambulatory adolescents and young adults with cerebral palsy. J Neuroeng Rehabil. 2014;11:49.

6. Lauruschkus K, Westbom L, Hallstrom I, Wagner P, Nordmark E. Physical activity in a total population of children and adolescents with cerebral palsy. Res Dev Disabil. 2013;34(1):157-67.

7. Noble JJ, Fry NR, Lewis AP, Keevil SF, Gough M, Shortland AP. Lower limb muscle volumes in bilateral spastic cerebral palsy. Brain and Development. 2014:36(4):294-300.

8. Moreau NG, Teefey SA, Damiano DL. In vivo muscle architecture and size of the rectus femoris and vastus lateralis in children and adolescents with cerebral palsy. Dev Med Child Neurol. 2009;51(10):800-6.

9. Verschuren O, Peterson MD, Balemans AC, Hurvitz EA. Exercise and physical activity recommendations for people with cerebral palsy. Dev Med Child Neurol. 2016:58(8):798-808.

10. Neufer PD, Bamman MM, Muoio DM, et al. Understanding the cellular and molecular mechanisms of physical activity-induced health benefits. Cell Metab. 2015;22(1):4-11.

11. Ryan JM, Peterson MD, Ryan N, et al. Mortality due to cardiovascular disease, respiratory disease, and cancer in adults with cerebral palsy. Dev Med Child Neurol. 2019;61(8):924-8.

12. Peterson MD, Ryan JM, Hurvitz EA, Mahmoudi E. Chronic conditions in adults with cerebral palsy. JAMA. 2015;314(21):2303-5.

13. Waltersson L, Rodby-Bousquet E. Physical activity in adolescents and young adults with cerebral palsy. Biomed Res Int. 2017;2017:8080473.

14. Rosenbaum $P$. The natural history of gross motor development in children with cerebral palsy aged 1 to 15 years. Dev Med Child Neurol. 2007:49(10): 724.

15. Hagglund G, Wagner P. Spasticity of the gastrosoleus muscle is related to the development of reduced passive dorsiflexion of the ankle in children with cerebral palsy: a registry analysis of 2,796 examinations in 355 children. Acta Orthop. 2011:82(6):744-8.

16. Noorkoiv M, Lavelle $\mathrm{G}$, Theis $\mathrm{N}$, et al. Predictors of walking efficiency in children with cerebral palsy: lower-body joint angles, moments, and power. Phys Ther. 2019;99(6):711-20

17. van der Linden ML, Jahed S, Tennant N, Verheul MHG. The influence of lower limb impairments on RaceRunning performance in athletes with hypertonia, ataxia or athetosis. Gait Posture. 2018;61:362-7.

18. Bolster EA, Dallmeijer AJ, de Wolf GS, Versteegt M, Schie PE. Reliability and construct validity of the 6-minute Racerunner test in children and youth with cerebral palsy, GMFCS levels III and IV. Phys Occup Ther Pediatr. 2017; 37(2):210-21.

19. Calve T, Russo Junior DV, Barela AMF. Strategies adopted by younger and older adults while operating a non-pedal tricycle. Braz J Phys Ther. 2018;22(1):64-9.

20. Tanaka H, Monahan KD, Seals DR. Age-predicted maximal heart rate revisited. J Am Coll Cardiol. 2001;37(1):153-6.

21. Machado FA, Denadai BS. Validity of maximum heart rate prediction equations for children and adolescents. Arq Bras Cardiol. 2011;97(2):136-40.

22. Borg G. Perceived exertion as an indicator of somatic stress. Scand J Rehabil Med. 1970;2(2):92-8

23. Bohm H, Doderlein L. Gait asymmetries in children with cerebral palsy: do they deteriorate with running? Gait Posture. 2012;35(2):322-7.

24. American Academy of Orthopaedic Surgeons. Joint motion: method of measuring and recording. Edinburgh: Churchill Livingstone; 1988.

25. Bohannon RW, Smith MB. Interrater reliability of a modified Ashworth scale of muscle spasticity. Phys Ther. 1987;67(2):206-7.

26. Dresen MH, de Groot G, Mesa Menor JR, Bouman LN. Aerobic energy expenditure of handicapped children after training. Arch Phys Med Rehabil. 1985;66(5):302-6.

27. Unnithan VB, Katsimanis G, Evangelinou C, Kosmas C, Kandrali I, Kellis E. Effect of strength and aerobic training in children with cerebral palsy. Med Sci Sports Exerc. 2007;39(11):1902-9.

28. Lundberg A, Pernow B. The effect of physical training on oxygen utilization and lactate formation in the exercising muscle of adolescents with motor handicaps. Scand J Clin Lab Invest. 1970;26(1):89-96.

29. Nsenga AL, Shephard RJ, Ahmaidi S. Aerobic training in children with cerebral palsy. Int J Sports Med. 2013;34(6):533-7. 
30. Van den Berg-Emons RJ, Van Baak MA, Speth L, Saris WH. Physical training of school children with spastic cerebral palsy: effects on daily activity, fat mass and fitness. Int J Rehabil Res. 1998;21(2):179-94.

31. Verschuren O, Ketelaar M, Gorter JW, Helders PJ, Uiterwaal CS, Takken T. Exercise training program in children and adolescents with cerebral palsy: a randomized controlled trial. Arch Pediatr Adolesc Med. 2007;161(11):1075-81.

32. Berg K. Effect of physical activation and of improved nutrition on the body composition of school children with cerebral palsy. Acta Paediatr Scand Suppl. 1970;204(Suppl 204):253+.

33. Garber CE, Blissmer B, Deschenes MR, et al. American College of Sports Medicine position stand. Quantity and quality of exercise for developing and maintaining cardiorespiratory, musculoskeletal, and neuromotor fitness in apparently healthy adults: guidance for prescribing exercise. Med Sci Sports Exerc. 2011;43(7):1334-59.

34. Ozaki H, Loenneke JP, Thiebaud RS, Stager JM, Abe T. Possibility of leg muscle hypertrophy by ambulation in older adults: a brief review. Clin Interv Aging. 2013:8:369-75.

35. Harber MP, Konopka AR, Douglass MD, et al. Aerobic exercise training improves whole muscle and single myofiber size and function in older women. Am J Physiol Regul Integr Comp Physiol. 2009:297(5):R1452-9.

36. Kubo K, Ishida Y, Suzuki S, et al. Effects of 6 months of walking training on lower limb muscle and tendon in elderly. Scand J Med Sci Sports. 2008: 18(1):31-9.

37. Ozaki H, Sakamaki M, Yasuda T, et al. Increases in thigh muscle volume and strength by walk training with leg blood flow reduction in older participants. J Gerontol A Biol Sci Med Sci. 2011;66(3):257-63.

38. Verschuren O, Smorenburg ARP, Luiking Y, Bell K, Barber L, Peterson MD. Determinants of muscle preservation in individuals with cerebral palsy across the lifespan: a narrative review of the literature. I Cachexia Sarcopenia Muscle. 2018;9(3):453-64.

39. Murphy KP, Molnar GE, Lankasky K. Employment and social issues in adults with cerebral palsy. Arch Phys Med Rehabil. 2000;81(6):807-11.

\section{Publisher's Note}

Springer Nature remains neutral with regard to jurisdictional claims in published maps and institutional affiliations.

Ready to submit your research? Choose BMC and benefit from:

- fast, convenient online submission

- thorough peer review by experienced researchers in your field

- rapid publication on acceptance

- support for research data, including large and complex data types

- gold Open Access which fosters wider collaboration and increased citations

- maximum visibility for your research: over $100 \mathrm{M}$ website views per year

At $\mathrm{BMC}$, research is always in progress.

Learn more biomedcentral.com/submissions 